\title{
GMR
}

\section{Association of endothelin-1 gene polymorphisms with essential hypertension in a Chinese population}

\author{
Z. Fang, M. Li, Z. Ma and G. Tu \\ Department of Cardiology, The Fourth Affiliated Hospital of Nanchang University, \\ Jiangxi Province, China \\ Corresponding author: G. Tu \\ E-mail: tuguoshengprof@hotmail.com \\ Genet. Mol. Res. 16 (3): gmr16037446 \\ Received January 13, 2017 \\ Accepted April 24, 2017 \\ Published July 6, 2017 \\ DOI http://dx.doi.org/10.4238/gmr16037446 \\ Copyright (C) 2017 The Authors. This is an open-access article distributed under the terms of \\ the Creative Commons Attribution ShareAlike (CC BY-SA) 4.0 License.
}

\begin{abstract}
Endothelin-1 (ET-1) is the most potent endogenous vasoconstrictor and is involved in several vascular disorders such as hypertension. Its strong interaction with other vasoactive hormone systems suggests that the ET-1 gene $(E D N 1)$ is a potential candidate molecule that influences the risk of developing hypertension. Recently, two single nucleotide polymorphisms in EDN1 have been reported to be associated with hypertension: Lys198Asn and 3A/4A (-134delA) located in the 5'-untranslated region. To determine the association of these two polymorphisms with hypertension, we genotyped patients and controls $(\mathrm{N}=537)$ and compared the allele and genotype frequencies between groups. There was no significant difference in the genotype frequencies of these two polymorphisms between healthy controls and hypertension patients. Although previous reports have revealed a significant interaction between the END1 Lys198Asn (G/T) polymorphism and body mass index in association with hypertension, no such relationship was observed in the present study. Further, we compared blood pressure among hypertensive subjects and observed that neither systolic nor diastolic blood pressure was significantly associated with variations in the genotypes of the two single nucleotide polymorphisms. In summary, these two END1 polymorphisms do
\end{abstract}

Genetics and Molecular Research 16 (3): gmr16037446 
not appear to affect the development of hypertension in the Chinese population.

Key words: Endothelin; Hypertension; Single nucleotide polymorphism; Chinese

\section{INTRODUCTION}

Hypertension is becoming an increasingly serious public health problem worldwide (Banno et al., 2007). More than one in five adults develop hypertension, which is the most significant modifiable risk factor for heart disease and stroke. The onset of hypertension is influenced by both environmental and genetic factors, and a vast amount of research has been conducted to identify susceptibility loci in humans (Carretero and Oparil, 2000a,b). Nonetheless, no genetic polymorphism has been identified to date that is consistently associated with hypertension in humans. Endothelin-1 (ET-1) expression has been linked to resistance artery remodeling, suggesting that it may increase the risk of hypertension development (Schiffrin, 2000; Delarue et al., 2004; Dhaun et al., 2008; Barton and Yanagisawa, 2008). The ET-1 plasma level was higher in patients with essential hypertension than in normotensive subjects and paralleled the severity of target organ damage. The ET receptor gene was also found to be overexpressed in the arteries of hypertensive patients, which suggests that ET-1 contributes to the pathogenesis of hypertension by means of endothelial dysfunction or proliferation of vascular smooth muscle cells (Yanagisawa et al., 1988; Shichiri et al., 1990; Schiffrin and Thibault, 1991; Schiffrin et al., 1997). Further support for the association between ET-1 and hypertension comes from a study demonstrating that treatment with an ET receptor antagonist for chronic hypertensive patients reduced blood pressure (Ergul et al., 1996; Tiret et al., 1999; Iglarz et al., 2002). Collectively, these several lines of evidence implicate a role for ET-1 in hypertension; therefore, the ET-1 gene (EDNI) has been proposed as a candidate risk factor for hypertension (Fan et al., 2012). In the present study, to examine the effect of polymorphisms of $E D N 1$ on the risk of hypertension, we analyzed the association between two EDN1 variants, a $138 \mathrm{~A}$ insertion/deletion (I/D) and the 5665G/T transversion (Lys198Asn), and hypertension in a large Chinese population.

\section{MATERIAL AND METHODS}

\section{Ethics statement}

This study was approved by the Ethics Committee of the Fourth Affiliated Hospital of Nanchang University. Written informed consent was obtained from all participants before the start of the study.

\section{Study population}

A total of 423 hypertensive subjects (281 men and 142 women; average age: $59.1 \pm$ 10.5 years) were recruited from the Fourth Hospital of Nanchang University. Normotensive subjects among 114 healthy volunteers ( 76 men and 38 women; average age, $58.5 \pm 9.4$ years) were selected randomly. Each subject was assigned to one of the blood pressure diagnostic

Genetics and Molecular Research 16 (3): gmr16037446 
categories defined by the following criteria. Hypertensive subjects had a previous diagnosis of hypertension and were being treated with antihypertensive medication, or their systolic/ diastolic blood pressure (SBP/DBP) was $>140 / 90 \mathrm{mmHg}$. Normotensive subjects had never been treated with medication for hypertension, and their SBP/DBP was $<140 / 90 \mathrm{mmHg}$.

\section{Clinical data and survey of life habits}

Using a standard mercury sphygmomanometer, the same nurse measured blood pressure twice consecutively with a 5 -min interval in seated subjects who had rested for $\geq 5$ min. Phase I and Phase V Korotkoff sounds were recorded as SBP and DBP, respectively. The mean value of the two measurements was used as the blood pressure value. Body mass index (BMI), measured as body weight $(\mathrm{kg})$ divided by height squared $\left(\mathrm{m}^{2}\right)$, was used to categorize subjects as obese or not, where obesity was defined as BMI $\geq 25 \mathrm{~kg} / \mathrm{m}^{2}$. Blood samples were drawn into disposable plastic vacuum tubes from a peripheral vein. Serum total cholesterol (TC), low-density lipoprotein-cholesterol (LDL-C), and fasting blood sugar (FBS) were measured using an autoanalyzer (SIEMENS ADVIL 2400, USA) and determined enzymatically using commercial enzyme kits (SIEMENS original reagent, USA). Smoking and alcohol drinking habits were assessed using a questionnaire on lifestyle factors.

\section{DNA samples}

Genomic DNA from the blood samples was extracted using a Qiagen kit (Qiagen Sciences, Germantown, MD, USA). We genotyped two single nucleotide polymorphisms (SNPs: A138I/D and Lys198Asn) by polymerase chain reaction-direct sequencing using the ABI-3100 sequencer (Applied Biosystems, Foster City, CA, USA). Specific primers were designed based on genomic sequences containing these SNPs obtained from GenBank (rs5370, rs10478694), and primer sequences are shown in Table 1. Information on thermal cycling conditions will be provided on request.

Table 1. Primer sequences for amplification of two single nucleotide polymorphisms of the endothelin-1 gene.

\begin{tabular}{l|l}
\hline Name of primer & Nucleotide sequences \\
\hline+138 insA/delA (rs10478694) Forward & 5'-TTCTCTCCTGGCAGG-3' $^{\prime}$ \\
\hline+138 insA/delA (rs10478694) Reverse & 5'-ATCTCAAAGCGATCCTTC-3' \\
\hline G198T (rs5370) Forward & 5'-TCTTTTGCCAAAGGGTGATT-3' \\
\hline G198T (rs5370) Reverse & 5'-CAGGGTGGAGAGTGCAGAG-3' \\
\hline
\end{tabular}

\section{Statistical analysis}

The quantitative variables for clinical characteristics are presented as means $\pm \mathrm{SD}$ and were analyzed using an unpaired Student $t$-test. For each SNP, the distribution of genotypes in patients and controls was tested for deviations from Hardy-Weinberg equilibrium by a chisquare test. Statistical analysis was performed with the use of Fisher's exact test. A value of $\mathrm{P}<0.05$ was considered significant. Odds ratios and $95 \%$ confidence intervals were used to estimate the risk of association with genotypes. The chi-square test for association was used to evaluate the difference in genotype frequencies between healthy controls and hypertension patients.

Genetics and Molecular Research 16 (3): gmr16037446 


\section{RESULTS}

The distribution of sex and lifestyle factors, as well as various quantitative variables (age, BMI, TC, LDL-C, FBS, SBP, DBP) in healthy controls and hypertension patients are shown in Table 2. Except for sex distribution and age, all variables were significantly different between the two groups $(\mathrm{P}<0.01)$, in which the mean values were higher in cases than in controls for all parameters tested. The proportion of incident cases of hypertension was larger among alcohol drinkers and smokers than among nondrinkers and nonsmokers $(\mathrm{P}<0.001$ for both).

\begin{tabular}{|c|c|c|c|}
\hline & Cases & Controls & $\mathrm{P}$ value \\
\hline $\mathrm{N}$ & 423 & 114 & \\
\hline Age (years) & $59 \pm 10.5$ & $58.5 \pm 9.4$ & $>0.05$ \\
\hline Gender (M) & $281(66.4 \%)$ & $76(66.7 \%)$ & $>0.05$ \\
\hline BMI $\left(\mathrm{kg} / \mathrm{m}^{2}\right)$ & $23.2 \pm 3.0$ & $21.1 \pm 2.5$ & $<0.001$ \\
\hline $\mathrm{TC}(\mathrm{mM})$ & $5.2 \pm 1.5$ & $4.1 \pm 1.1$ & $<0.001$ \\
\hline LDL-C (mM) & $3.15 \pm 0.68$ & $2.93 \pm 0.55$ & $<0.01$ \\
\hline FBS (mM) & $5.52 \pm 2.23$ & $4.25 \pm 1.98$ & $<0.001$ \\
\hline Alcohol drinking & $290(68.6 \%)$ & $40(35.1 \%)$ & $<0.001$ \\
\hline Smoking & $279(66.0 \%)$ & $36(31.6 \%)$ & $<0.001$ \\
\hline $\mathrm{SBP}(\mathrm{mmHg})$ & $161.5 \pm 19.4$ & $118.2 \pm 11.7$ & $<0.001$ \\
\hline DBP (mmHg) & $95.4 \pm 11.7$ & $75.6 \pm 7.8$ & $<0.001$ \\
\hline
\end{tabular}

BMI, body mass index; TC, total cholesterol; LDL-C, low-density lipoprotein cholesterol; FBS, fasting blood sugar; SBP, systolic blood pressure; DBP, diastolic blood pressure.

Two previously known polymorphisms associated with hypertension were detected in END1: a) an "A" insertion (I)/deletion (D) in exon 1 at position +138 (rs10478694), designated as 3A/3A (wild type/deletion), 3A/4A, 4A/4A (mutation/insertion); and b) a G/T transversion at position +5665 (rs5370) affecting the 61 st nucleotide of exon 5 , which results in substitution of a Lys residue at codon 198 with Asn (K198N). The latter polymorphism is commonly designated as - Lys198Lys, Lys198Asn, Asn198Asn. We designed primers to analyze the genotype and allele frequencies for these two polymorphisms in patients and normal controls and conducted a case-control comparison. Polymorphisms 138AI/D and 5665G/T (Lys198Asn) of END1 were in Hardy-Weinberg equilibrium $(\mathrm{P}>0.05)$ in patients and normal controls. The genotype frequencies of these two SNPs in hypertension cases and healthy controls are summarized in Table 3.

Table 3. Associations of genotypes and alleles of two single nucleotide polymorphisms (SNPs) of END-1 in with risk of hypertension in all subjects.

\begin{tabular}{|c|c|c|c|c|c|c|c|c|c|c|}
\hline \multirow{2}{*}{\multicolumn{2}{|c|}{$\mathrm{SNP}^{1}$}} & \multirow[t]{3}{*}{$\mathrm{N}^{2}$} & \multicolumn{5}{|c|}{ Genotype frequency } & \multicolumn{3}{|c|}{ Allele frequency } \\
\hline & & & & Genotype & & P value $^{3}$ & OR $(95 \% \mathrm{CI})^{4}$ & Allele & $\mathrm{P}$ value $^{5}$ & OR $(95 \% \mathrm{CI})^{4}$ \\
\hline \multirow[t]{3}{*}{+138 ins $\mathrm{A} /$ delA } & & & $3 \mathrm{~A} 4 \mathrm{~A}$ & $3 \mathrm{~A} / 3 \mathrm{~A}$ & $4 \mathrm{~A} / 4 \mathrm{~A}$ & & \multirow{3}{*}{$\begin{array}{c}1.29 \\
(0.80-2.09)\end{array}$} & $4 \mathrm{~A}$ & & \multirow{3}{*}{$\begin{array}{c}0.96 \\
(0.71-1.30)\end{array}$} \\
\hline & Cases & 423 & 0.295 & 0.438 & 0.267 & 0.340 & & 0.486 & 0.819 & \\
\hline & Controls & 114 & 0.246 & 0.517 & 0.237 & & & 0.496 & & \\
\hline \multirow[t]{3}{*}{ G198T } & & & $\mathrm{G} / \mathrm{G}$ & $\mathrm{G} / \mathrm{T}$ & $T / T$ & & \multirow{3}{*}{$\begin{array}{c}0.84 \\
(0.51-1.37)\end{array}$} & $\mathrm{T}$ & & \multirow{3}{*}{$\begin{array}{c}1.28 \\
(0.81-2.01)\end{array}$} \\
\hline & Cases & 423 & 0.730 & 0.247 & 0.023 & 0.541 & & 0.146 & 0.323 & \\
\hline & Controls & 114 & 0.763 & 0.237 & 0.000 & & & 0.118 & & \\
\hline
\end{tabular}

OR, odds ratio; $95 \% \mathrm{CI}, 95 \%$ confidence interval. ${ }^{1} \mathrm{SNP}$ name for genotype in cases and controls. ${ }^{2}$ Number of valid subjects who were successfully genotyped for each SNP. ${ }^{3}$ Analysis performed by a 2 x 2 table for each SNP using major homozygotes vs others in cases and controls. ${ }^{4}$ Reference group (controls) designated with an OR of 1.00 . ${ }^{5}$ Analysis performed by a $2 \times 2$ table for the number of each allele in cases and controls. 
For the $3 \mathrm{~A} / 4 \mathrm{~A}$ polymorphism, the frequency of heterozygotes $(3 \mathrm{~A} / 4 \mathrm{~A})$ among hypertension patients $(43.8 \%)$ was similar to that in the healthy controls $(51.7 \%)$. In addition, the odds ratio for the dominant model was not statistically significant in the hypertension patients $(\mathrm{P}=0.819)$. Similarly, there was no significant difference in the distribution of allele and genotype frequencies for the Lys198Asn polymorphism in exon 5 between hypertension patients and healthy controls (Table 3). These results indicate that there are no associations between the genotype distributions of these two SNPs and hypertension risk in the Chinese population.

To further investigate the relationship between the selected SNPs and essential hypertension, we measured SBP and DBP among hypertensive subjects and found no association between blood pressure and genotypes of either SNP (Table 4).

In contrast to previous reports, there was no significant interaction between the Lys198Asn (G/T) polymorphism and BMI in association with hypertension in the present study (Table 5).

Table 4. Association of genotypes of the two END1 single nucleotide polymorphism with blood pressure in hypertension patients.

\begin{tabular}{l|c|c|c|c|c|c}
\hline & \multicolumn{3}{|c|}{+ 138insA/delA } & \multicolumn{3}{c}{ G198T } \\
\cline { 2 - 7 } & $3 \mathrm{~A} / 3 \mathrm{~A}(\mathrm{~N}=185)$ & $3 \mathrm{~A} / 4 \mathrm{~A}+4 \mathrm{~A} / 4 \mathrm{~A}(\mathrm{~N}=238)$ & $\mathrm{P}$ value & $\mathrm{G} / \mathrm{G} \mathrm{N}=309$ & $\mathrm{G} / \mathrm{T}+\mathrm{T} / \mathrm{T}(\mathrm{N}=114)$ & $\mathrm{P}$ value \\
\hline SBP $(\mathrm{mmHg})$ & $159.2 \pm 17.3$ & $162.1 \pm 20.4$ & 0.112 & $161.7 \pm 16.5$ & $158.4 \pm 14.5$ & 0.065 \\
\hline DBP $(\mathrm{mmHg})$ & $96.2 \pm 12.5$ & $94.6 \pm 10.2$ & 0.148 & $96.6 \pm 9.8$ & $94.8 \pm 10.9$ & 0.122 \\
\hline
\end{tabular}

SBP, systolic blood pressure; DBP, diastolic blood pressure.

Table 5. Distribution of the genotypes of the two END1 polymorphisms according to body mass index (BMI).

\begin{tabular}{|c|c|c|c|c|c|c|}
\hline \multirow[t]{2}{*}{ SNP } & \multirow[t]{2}{*}{ Genotype } & \multicolumn{2}{|c|}{ Cases $(\mathrm{N}=423)$} & \multicolumn{2}{|c|}{ Controls $(\mathrm{N}=114)$} & \multirow[t]{2}{*}{ P value (case $v s$ control) } \\
\hline & & $\mathrm{BMI} \geq 25 \mathrm{~kg} / \mathrm{m}^{2}$ & $\mathrm{BMI}<25 \mathrm{~kg} / \mathrm{m}^{2}$ & $\mathrm{BMI} \geq 25 \mathrm{~kg} / \mathrm{m}^{2}$ & $\mathrm{BMI}<25 \mathrm{~kg} / \mathrm{m}^{2}$ & \\
\hline \multirow[t]{3}{*}{+138 insA/delA } & $3 \mathrm{~A} / 3 \mathrm{~A}$ & $98(0.232)$ & $87(0.206)$ & $34(0.298)$ & $25(0.219)$ & 0.532 \\
\hline & $3 \mathrm{~A} / 4 \mathrm{~A}$ & $58(0.137)$ & $67(0.158)$ & $12(0.105)$ & $16(0.141)$ & 0.734 \\
\hline & $4 \mathrm{~A} / 4 \mathrm{~A}$ & $50(0.188)$ & $63(0.149)$ & $11(0.096)$ & $16(0.141)$ & 0.741 \\
\hline \multirow[t]{3}{*}{ G198T } & $\mathrm{G} / \mathrm{G}$ & $175(0.413)$ & $134(0.317)$ & $53(0.465)$ & $34(0.298)$ & 0.475 \\
\hline & $\mathrm{G} / \mathrm{T}$ & $65(0.154)$ & $39(0.093)$ & $16(0.140)$ & $11(0.097)$ & 0.757 \\
\hline & $\mathrm{T} / \mathrm{T}$ & $7(0.016)$ & $3(0.007)$ & $0(0.000)$ & $0(0.000)$ & \\
\hline
\end{tabular}

\section{DISCUSSION}

Association studies are often irreproducible among populations; therefore, replication studies in large populations are indispensable to establishing an association between a gene and disease. Despite the wealth of information obtained from animal models and pharmacological interventions supporting a role of ET-1 as a significant factor in hypertension, the direct relationship of ET-1 plasma levels to hypertension remains controversial (Jin et al., 2003). Further support for this relationship has been provided based on associations of EDN1 polymorphisms with hypertension. Previous research has predominantly focused on the Lys198Asn polymorphism as a possible risk factor, with the $\mathrm{T}$ allele being associated with increased blood pressure in several studies of European, Australian, Japanese, and American subjects (Barden et al., 2001). Several reports have described that the Lys198Asn polymorphism in EDN1 showed a positive association with blood pressure elevation in overweight people, both in Caucasians and Japanese subjects (Pinto-Sietsma et al., 2003). Another study focusing on pregnant women showed that the Asn allele was associated with hypertension, and homozygotes with Asn198 had a significantly increased plasma ET-1 level

Genetics and Molecular Research 16 (3): gmr16037446 
compared to women with other genotypes (Colombo et al., 2006). These studies suggested that the Lys198Asn polymorphism may affect hypertension regulation through the production of ET-1. In the present study, we analyzed the association between two END1 gene variants, 138AI/D and 5665G/T (Lys198Asn), and hypertension in one large Chinese population. We genotyped the patients and controls $(\mathrm{N}=537)$ and compared the allele and genotype frequencies between groups. We found that there was no significant difference in the genotype frequencies of these two polymorphisms between healthy controls and hypertension patients. These results suggest that these two polymorphisms do not play a major role in hypertension development in the Chinese population. These results also suggest that although the END1 polymorphism itself may not influence the risk of hypertension, it may nevertheless be involved in the pathogenesis in combination with another genetic variant in linkage disequilibrium with it in the Chinese population. Although ET-1 is known to be a strong vasoconstrictive agent in vitro, there has been no direct evidence showing a causative effect of END1 in hypertension reported to date. Several reports suggest that an increase in ET-1 concentration is associated with progression of hypertension and that high blood pressure promotes an increase in ET-1, but these results are subject to debate (Böhm et al., 2002).

Thus far, the interaction between the Lys198Asn polymorphism and BMI in association with blood pressure and hypertension has been assessed in five large populations (Tanaka et al., 2004; Bühler et al., 2007). Although these populations were evaluated with different study designs and show different overall characteristics, including BMI and ethnicity, all of the results showed a similar trend, suggesting the presence of an interaction. Given these several lines of biological evidence from different populations, END1 has been proposed as a promising candidate gene for influencing the risk of hypertension development (Fan et al., 2012). The lack of a significant interaction between the END1 Lys198Asn polymorphism and hypertension in the present study may be due to the unstable nature of blood pressure and the presence of treated hypertensive subjects in this cohort. Thus, in some populations, blood pressure may be an informative variable, but could provide less accurate information compared to categorical hypertension status.

However, no previous study had examined the functional consequence of the -134delA polymorphism in END1. Because the -134delA polymorphism is located in the non-coding region of the $E D N 1$ gene, it is likely that the polymorphism results in modification of gene expression or influences the stability of the mRNA rather than directly impacting its function.

In conclusion, our results indicate that there is no significant association of the EDN1 Lys198Asn and -134delA polymorphisms with hypertension in the Chinese population. Therefore, we propose that another variant in linkage disequilibrium with this polymorphism might be responsible for the association with hypertension via plasma ET-1 up-regulation, or that an interaction between the EDN1 Lys198Asn polymorphism and other factors such as obesity might be involved in the mechanisms contributing to elevating blood pressure in vivo.

\section{Conflicts of interest}

The authors declare no conflict of interest.

\section{ACKNOWLEDGMENTS}

We thank Dr Xiaoshu Cheng for providing assistance in this research.

Genetics and Molecular Research 16 (3): gmr16037446 


\section{REFERENCES}

Banno M, Hanada H, Kamide K, Kokubo Y, et al. (2007). Association of genetic polymorphisms of endothelin-converting enzyme-1 gene with hypertension in a Japanese population and rare missense mutation in preproendothelin-1 in Japanese hypertensives. Hypertens. Res. 30: 513-520. https://doi.org/10.1291/hypres.30.513

Barden AE, Herbison CE, Beilin LJ, Michael CA, et al. (2001). Association between the endothelin-1 gene Lys198Asn polymorphism blood pressure and plasma endothelin-1 levels in normal and pre-eclamptic pregnancy. J. Hypertens. 19: 1775-1782. https://doi.org/10.1097/00004872-200110000-00011

Barton M and Yanagisawa M (2008). Endothelin: 20 years from discovery to therapy. Can. J. Physiol. Pharmacol. 86: 485-498. https://doi.org/10.1139/Y08-059

Böhm F, Ahlborg G, Johansson BL, Hansson LO, et al. (2002). Combined endothelin receptor blockade evokes enhanced vasodilatation in patients with atherosclerosis. Arterioscler. Thromb. Vasc. Biol. 22: 674-679. https://doi. org/10.1161/01.ATV.0000012804.63152.60

Bühler K, Ufer M, Müller-Marbach A, Brinkmann U, et al. (2007). Risk of coronary artery disease as influenced by variants of the human endothelin and endothelin-converting enzyme genes. Pharmacogenet. Genomics 17: 77-83. https://doi.org/10.1097/01.fpc.0000230118.26581.40

Carretero OA and Oparil S (2000a). Essential hypertension. Part I: definition and etiology. Circulation 101: 329-335. https://doi.org/10.1161/01.CIR.101.3.329

Carretero OA and Oparil S (2000b). Essential hypertension: part II: treatment. Circulation 101: 446-453. https://doi. org/10.1161/01.CIR.101.4.446

Colombo MG, Ciofini E, Paradossi U, Bevilacqua S, et al. (2006). ET-1 Lys198Asn and ET(A) receptor H323H polymorphisms in heart failure. A case-control study. Cardiology 105: 246-252. https://doi.org/10.1159/000092374

Delarue C, Conlon JM, Remy-Jouet I, Fournier A, et al. (2004). Endothelins as local activators of adrenocortical cells. $J$. Mol. Endocrinol. 32: 1-7. https://doi.org/10.1677/jme.0.0320001

Dhaun N, Goddard J, Kohan DE, Pollock DM, et al. (2008). Role of endothelin-1 in clinical hypertension: 20 years on. Hypertension 52: 452-459. https://doi.org/10.1161/HYPERTENSIONAHA.108.117366

Ergul S, Parish DC, Puett D and Ergul A (1996). Racial differences in plasma endothelin-1 concentrations in individuals with essential hypertension. Hypertension 28: 652-655. https://doi.org/10.1161/01.HYP.28.4.652

Iglarz M, Benessiano J, Philip I, Vuillaumier-Barrot S, et al. (2002). Preproendothelin-1 gene polymorphism is related to a change in vascular reactivity in the human mammary artery in vitro. Hypertension 39: 209-213. https://doi. org/10.1161/hy0202.103442

Fan XH, Wang H, Gao LG, Sun K, et al. (2012). The association of an adenine insertion variant in the 5'UTR of the endothelin-1 gene with hypertension and orthostatic hypotension. Arch. Med. Sci. 8: 219-226. https://doi.org/10.5114/ $\underline{\text { aoms.2012.28548 }}$

Jin JJ, Nakura J, Wu Z, Yamamoto M, et al. (2003). Association of endothelin-1 gene variant with hypertension. Hypertension 41: 163-167. https://doi.org/10.1161/01.HYP.0000043680.75107.CF

Pinto-Sietsma SJ, Herrmann SM, Schmidt-Petersen K, Niu T, et al. (2003). Role of the endothelin-1 gene locus for renal impairment in the general nondiabetic population. J. Am. Soc. Nephrol. 14: 2596-2602. https://doi.org/10.1097/01. ASN.0000089827.03201.8E

Schiffrin EL (2000). Endothelin: role in experimental hypertension. J. Cardiovasc. Pharmacol. 35 (Suppl 2): S33-S35. https://doi.org/10.1097/00005344-200000002-00008

Schiffrin EL, Deng LY, Sventek P and Day R (1997). Enhanced expression of endothelin-1 gene in resistance arteries in severe human essential hypertension. J. Hypertens. 15: 57-63. https://doi.org/10.1097/00004872-199715010-00005

Schiffrin EL and Thibault G (1991). Plasma endothelin in human essential hypertension. Am. J. Hypertens. 4: 303-308. https://doi.org/10.1093/ajh/4.4.303

Shichiri M, Hirata Y, Ando K, Emori T, et al. (1990). Plasma endothelin levels in hypertension and chronic renal failure. Hypertension 15: 493-496. https://doi.org/10.1161/01.HYP.15.5.493

Tiret L, Poirier O, Hallet V, McDonagh TA, et al. (1999). The Lys198Asn polymorphism in the endothelin-1 gene is associated with blood pressure in overweight people. Hypertension 33: 1169-1174. https://doi.org/10.1161/01. HYP.33.5.1169

Tanaka C, Kamide K, Takiuchi S, Kawano Y, et al. (2004). Evaluation of the Lys198Asn and -134delA genetic polymorphisms of the endothelin-1 gene. Hypertens. Res. 27: 367-371. https://doi.org/10.1291/hypres.27.367

Yanagisawa M, Kurihara H, Kimura S, Tomobe Y, et al. (1988). A novel potent vasoconstrictor peptide produced by vascular endothelial cells. Nature 332: 411-415. https://doi.org/10.1038/332411a0

Genetics and Molecular Research 16 (3): gmr16037446 